\title{
Community Disaster Management Assets: A Case Study of the Farm Community in Sussex County, Delaware
}

\author{
Yvonne Rademacher* \\ Disaster Research Center, University of Delaware, DE 19701, U.S.A.
}

\begin{abstract}
While government mandates and programs continue to expand to meet the increasing challenges of disaster management, there is growing recognition that government cannot do it all alone. This has led to a quest to better understand local capacities, through partnerships with the private sector and volunteer organizations but also in relation to individual citizens. The Federal Emergency Management Agency's (FEMA) recent Whole Community initiative constitutes a policy shift towards more local engagement and responsibility. However, before devising strategies to better engage and support various actors, the nature of their disaster management resources needs to be more clearly understood. What disaster management resources do communities supply? This case study examined the assets of one community group, the farm community in Sussex County, Delaware. The conceptual framework was based on a community asset approach, which currently recognizes eight types of community capital and is comprised of active, inactive, positive, and negative resources. The study found a striking discrepancy between actually used and perceived community resources. Farm community resources were primarily used for implementation activities during disaster preparedness. The types of resources used fell into three broad categories: equipment/ supplies; experience/lessons learned; and access to other community and professional networks. The findings highlighted the use of four community capitals-human, social, physical, financial-and the existence of active, inactive, negative, and positive resources. Tools currently employed to register community resources, such as the National Incident Management System (NIMS) resource inventory management for rural communities, are designed for professional emergency services but do not recognize the full range of potentially relevant community assets.
\end{abstract}

Keywords community assets, Delaware, disaster management resources, FEMA, NIMS

\section{Introduction}

Statistics show that disaster losses and the number of complex disasters are on the rise in the United States, as in the rest of the world (Board on Natural Disasters 1999; Cutter

\footnotetext{
*E-mail:vonnie@udel.edu
}

and Emrich 2005; UN 2011). The United States government acknowledges that it cannot meet these challenges alone (DHS 2009). One of the recent initiatives of the Federal Emergency Management Agency (FEMA) is the Whole Community approach. While policies are still in the development stage, FEMA $(2011,3)$ understands it to be

a means by which residents, emergency management practitioners, organizational and community leaders, and government officials can collectively understand and assess the needs of their respective communities and determine the best ways to organize and strengthen their assets, capacities, and interests.

In developing the Whole Community concept, FEMA explains that understanding community capabilities is one of the challenges (FEMA 2011). In order to effectively engage diverse groups in disaster management, information about the availability of all resources from every stakeholder is critical. While government already collaborates closely with the voluntary sector and also increasingly and more comprehensively with the private sector, we know little about the resources of the rest of the community - of individual citizens and the range of community groups that it comprises. Apart from maintaining a roster of those who, for example, have had first aid training or are members of a Community Emergency Response Team (CERT), what other resources do community members possess that can contribute to disaster management? And how do they understand their own disaster management resources?

It is not sufficient to consider those physical assets, skills, and experiences, which citizens individually and community groups collectively have employed in the past. These may not be representative of all assets that exist and have the potential for activation. For the process of planning with community disaster management resources to be meaningful, it is important to understand the full range of potential resources. Before attempting to devise strategies of how to tap into the currently unused or underused resources, an understanding has to be gained about what specific types of resources are available, that is, the nature of community assets that have the potential of contributing to disaster management. With this knowledge, we can then look into ways of how to best make use of them. 
The purpose of this case study was to further examine this knowledge gap of understanding community disaster management resources and contribute to the discussion on FEMA's policy development of the Whole Community. The farm community in Sussex County, Delaware, was selected as an ethnographic case study. The agriculture sector has had experience with all types of disasters for centuries, even before government started assuming responsibilities and set up institutions to manage them. For this reason, this community group was of particular interest. Sussex County is the agriculture center in the state of Delaware, and farmers represent a majority group in the local population.

Three specific research questions were pursued:

(1) How does the farm community in Sussex County perceive its own capacity to engage in disaster mitigation, preparedness, response, and recovery?

(2) How has the farm community in Sussex County employed its own resources in past disasters?

(3) How do the resources of the farm community in Sussex County relate to the functional areas of institutional disaster management?

The significance of this study is multifaceted. It intended to advance research by moving from a social capital to a community asset approach. Through a better understanding of the nature of specific community resources, a new perspective may also be gained for other related concepts such as disaster vulnerability and resilience. Better information on the nature of community resources may shed light on communities' resilience in certain areas to withstand the impact of a disaster, and it may also highlight weaknesses in terms of a lack of resources that will require attention. This study also hoped to offer a refined conceptual view of community disaster management resources and thus address FEMA's stated challenge of understanding community capabilities. Society cannot afford to further delay where significant advances can be made in managing disasters - particularly through the inherent resources of major stakeholders such as communities themselves. In the current political and economic climate, an expansion of government services is unlikely and unrealistic. The use of the Whole Community's disaster management assets is needed.

\section{Literature Review}

In seeking answers to the three research questions, the literature review focused on two major bodies of literature: theoretical concepts of community assets; and public policy conceptualization of community disaster management resources.

\subsection{The Theoretical Concepts of Community Assets}

Research into community disaster management resources is currently seen through three distinct but closely intertwined lenses: social vulnerability-focused on social factors that create inequality and unequal access to resources for segments of the population and leave some more susceptible to the impact of disasters; resilience- focused on a community's positive recovery capacities and the degree to which it is capable of bouncing back from the effects of a disaster with its own resources; and social capital - one component of community assets that constitutes the aggregate of positive as well as negative community resources and represents the actual community capacity to cope with disasters, reflecting the characteristics of social vulnerability and resilience.

Whereas early disaster research (Quarantelli and Dynes 1971) studied social cohesion and community strength in terms of response capacities in times of calamities, the focus shifted in the late 1970s to a perspective of predisaster social vulnerabilities that negatively affect a community's capacity to respond (O'Keefe, Westgate, and Wisner 1976; Cutter, Boruff, and Shirley 2003). One of the underlying views at the time was that the social cohesion approach was only conceptually appropriate for natural disasters but not sufficient to also adequately capture the rapid changes in society and the new threats of manmade and technological disasters. Proponents of the vulnerability approach believed that "rather than leading to the emergence of solidarity, technological disasters have helped create a 'corrosive community'. Blame, mutual recrimination and conflict are presented as the consequence of technologically driven disasters" (Furedi 2007, 484) that have led to a breakdown of social cohesion, leaving communities more vulnerable to disasters. However, a closer look at community behavior in actual disasters has demonstrated that vulnerability as a concept is not sufficient either to explain a community's capacity, or lack thereof. Consequently, interest has returned to the broader concept of social capital and the development of resilience as the positive antidote to social vulnerability. This shift in thinking is supported by an increasing body of research over the last two decades of case studies that have uncovered disaster myths, which have-and often still do-described communities and their members largely as victims, "vulnerable" and "panicked"-while, in fact, it is reportedly the solidarity of community networks and the courage and calmness of individuals as first responders that make significant—-but unmeasured and largely unacknowledged - contributions to search and rescue and initial response activities (Quarantelli and Dynes 1971; Stone 2001; Murphy 2007). As Dynes $(2006,2)$ further explained:

The vocabulary of 'command and control' suggests chaos rather than citizen adaptability and creativity $[\ldots]$ while we calculate damage to physical and human capital, we usually ignore the social capital available within communities to deal with emergencies. Social capital is our most significant resource in responding to damage caused by natural and other hazards, such as terrorism.

Instead of treating any of the three approaches in isolation, there is increasing consensus that all three in conjunction provide invaluable insights into a community's capacity to 
cope with disasters. While all three are indispensable to understanding community disaster management assets, the focus of this study was on all the possible community assets and factors that influence the mobilization of resources. Its findings suggest that - instead of focusing on social capital as the only community capital significant to disaster management-a broader view of community assets recognizing all types of capitals may be more appropriate.

Coleman $(1988,1994)$ and Putnam, Leonardi, and Nanetti (1993) have widely been credited with developing the concept of "social capital" in the early 1990s. The following decade saw an understanding of social capital as only one type of capital that together with others comprises community assets. Currently, eight types of community capitals are recognized: human, social, physical, financial, environmental, political, cultural, and spiritual (Bourdieu 1986; Guest 2007; Green and Haines 2012). This literature understands individual community resources to be embedded in the various types of capital. As discussions among scientists persist on definitions for these different types of capital and their linkages and overlaps, for the purposes of this study, they are used and defined as follows:

(1) Human: including education, labor market experience, artistic development and appreciation, health, other skills and experiences;

(2) Social: trust, norms, social relationships and networks;

(3) Physical: possession of and capacity to maintain roads, buildings, railroad tracks, bridges, vacant land, and so on;

(4) Financial: access to tangible monetary assets, including loans and credits;

(5) Environmental: natural resources - air, water, land, flora, and fauna;

(6) Political: access to decision making through instrumental (influencing policies in one's interest) or structural (participatory attributes of the political system) political capital;

(7) Cultural: embodied, objectified, and institutionalized cultural assets;

(8) Spiritual: flow of ideas and values that emerge out of tradition and may be embodied, objectified, and institutionalized assets.

Possibly because of its origin in sociology, disaster studies in the United States have focused on social capital, that is, research on community networks and relationships that are used pre- and postdisaster. Little research has been carried out in relation to other types of community capitals - let alone a comprehensive study of all of a community's disaster management assets.

Resources that are embedded in these different types of community capitals can be categorized into active, inactive, positive, and negative. Hyman (2008, 226), by aggregating the conceptual approaches of social capital as developed by Bourdieu (1986), Coleman (1988, 1994), Portes (1998), Putnam (2000), and Putnam, Leonardi, and Nanetti (1993), defines positive social capital as "an asset representing actionable resources that are contained in, and accessible through a system of relationships." By qualifying community resources as "actionable" or capable of being acted upon, this definition recognizes not only those resources that have become active but also those that have the potential of being accessed through a system of relationships in the community.

Stone (2001) and Weissbourd, Bodini, and RW Ventures, LLC (2005) explore the importance of this broadened definition further. Stone $(2001,4-5)$ explains that locating and measuring social capital has focused, misguidedly, on "outcomes of social capital as indicators of social capital itself." Social capital has been said to exist whenever the outcome indicator is positive, which Stone describes as a "tautological fallacy." While Stone focuses on conceptual issues of measuring social capital that should not only consider outcomes but instead all contributing dimensions potentially leading to the formation of social capital, Weissbourd, Bodini, and RW Ventures, LLC approach the same issue through the lens of economics, in that "assets do not have a value per se; they are passive, or idle, until they are "acted on," or leveraged by businesses and investors. Neighborhood assets become valuable only to the extent that they are deployed or incorporated in a market-based economic process" $(2005,8)$. According to both above findings, social capital encompasses active, that is, used, as well as dormant, that is, potential, community resources. By extension, all other types of capital should also comprise active and inactive resources.

There is extensive interdisciplinary research on another attribute of community assets that explores its positive and negative characteristics. The most well-known of these is negative social capital. Portes $(1998,15)$ explains that "it is our sociological bias to see good things emerging out of sociability [...] However, the same mechanisms appropriable by individuals and groups as social capital can have other, less desirable consequences." Instead of only focusing on the positive impact of community networks, social control, and collective sanctions, Portes finds that they can also lead to the "exclusion of outsiders, excess claims on group members, restrictions on individual freedoms, and downward leveling norms" (1998, 15), leading to what he describes as negative social capital. Social networks can foster an environment conducive to criminal behavior that leads to a deterioration of human capital in the form of educational underachievement, deteriorating physical and mental well-being, and progressive exclusion from the work force. This literature demonstrates that each type of community capital has inherent in it the potential for positive as well as negative actionable resources. It also shows how closely the various capitals impact each other and can trigger the activation of either positive or negative resources in another type of capital.

This current state of research into community assets (Figure 1) - "actionable resources" as developed by Hyman; Stone; and Weissbourd, Bodini, and RW Ventures, LLC as well as Portes's "positive" and "negative" community resources - has helped inform the conceptual framework for this study. 


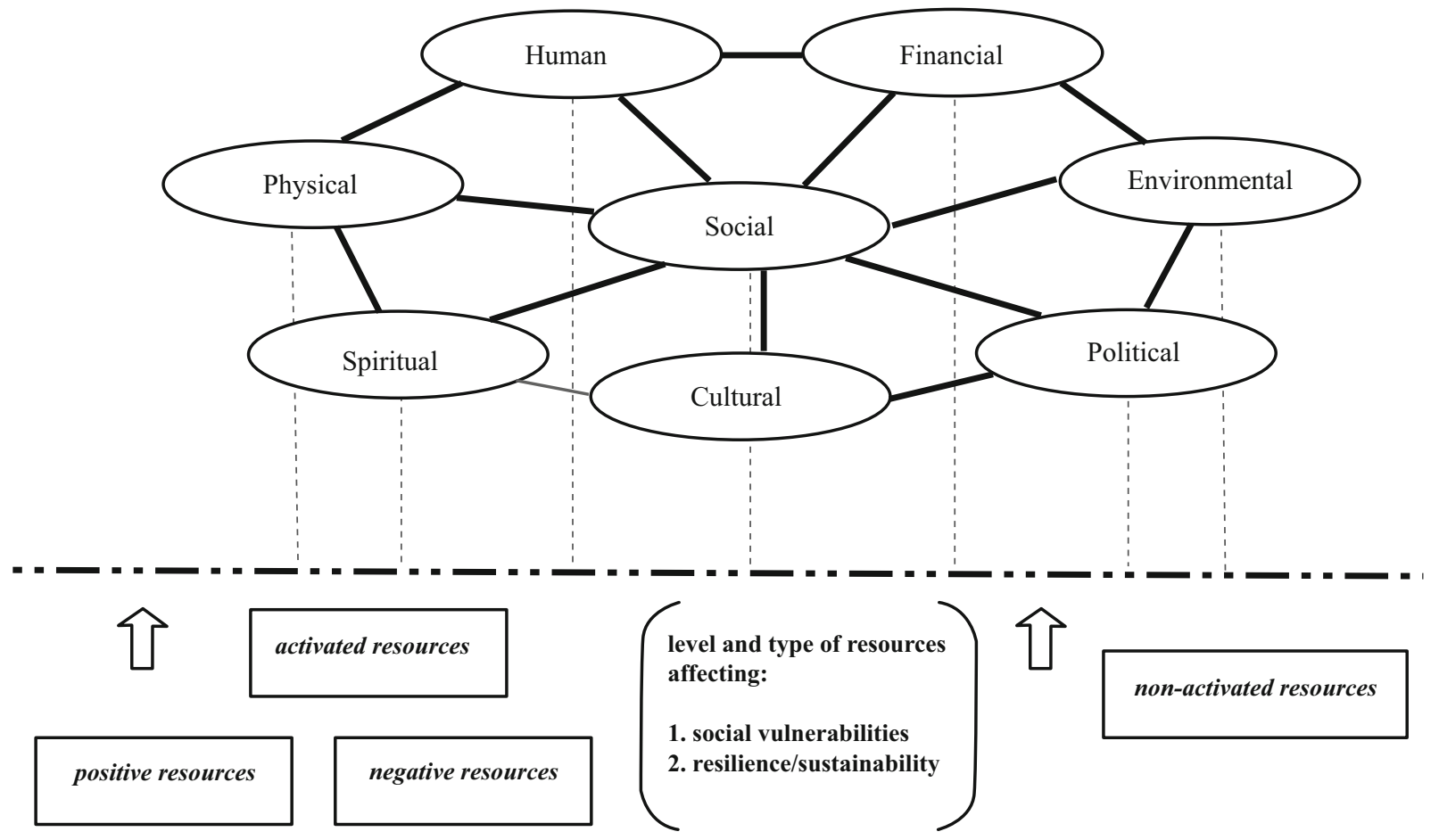

Figure 1. Community resources in the context of community assets

\subsection{Public Policy Conceptualization of Community Disaster Management Resources}

In public policy, the Federal Emergency Management Agency (FEMA) addresses rural resource management through the National Incident Management System (NIMS), established in 2003 with the aim to bring together government, private, and nongovernmental organizations for more coordinated emergency management. One of the areas of coordination is resource management, for which NIMS defines and uses eight broad categories of rural emergency management resources: animal health; emergency management; emergency medical services; fire/HazMat; helicopters, firefighting; law enforcement; public works; and search and rescue. These eight categories are further broken down into "kinds," which include trained personnel as well as equipment and supplies, such as public safety dive teams, hydraulic truck cranes, and air curtain burners.

FEMA (2010) explains that its rural emergency resource management system plays a role in mitigation, preparedness, and response. Its resources inventory in the above eight categories is focused on preparedness and response. Policies and guidelines related to NIMS resource management do not explicitly state what resources are intended in what phase of the disaster management cycle. It is unclear if policies and programs related to NIMS resource management consider all eight categories applicable to all phases of the disaster management cycle. For the development of the conceptual framework, further literature and emergency handbooks
(Lindell, Prater, and Perry 2007; Haddow, Bullock, and Coppola 2008) were reviewed.

For the purposes of this study, which intended to look at the community's resources in all four phases of the disaster management cycle, NIMS's eight broad categories of resource management were eventually juxtaposed with the typologies of emergency functions as summarized by Lindell, Prater, and Perry (2007). In order to simplify the data collection process and capture resources that could be provided not only by technical experts but also by nonprofessional community members with relevant experience, skills, and equipment, the functional areas were grouped together into four broad categories of activities that are relevant to all four phases of the disaster management cycle: assessment; coordination; communication/information management; and implementation/operations. For this study, they were defined as follows:

(1) Assessment: risk perception; assessing the magnitude, location, and timing of impact; loss and damage evaluation; and recommending how to respond and recover.

(2) Coordination: the process by which relevant group members consult with each other internally and externally with the objective of agreeing on and synchronizing a joint course of action to ensure the most efficient use of communal resources in pursuit of specified objectives.

(3) Communication/Information Management: mechanisms of timely and relevant information sharing between group members as well as with outside actors on the nature of threats, events that had taken place, any action taken by whom, how and when, as well as information on outstanding needs and gaps. 
(4) Implementation/Operations: the process of deployment of personnel, equipment and supplies, as well as in a broader sense, the application of knowledge and expertise, with the aim of either mitigating, preparing for, responding to, or recovering from a disaster event.

Based on the literature on community assets and the public policy conceptualization of community resources, a threedimensional framework was designed with the following components: (1) the four phases of the disaster management cycle, that is, mitigation, preparedness, response, and recovery; (2) perceived and actually used resources; and (3) the four broad categories of disaster management activities, that is, coordination, assessment, communication, and implementation.

\section{Methodology}

The identification process of disaster-relevant resources in this farm community was carried out through a three-step approach. A survey was conducted that looked into (1) the farm community's own perception of their disaster management resources; (2) the actual use of their resources in previous disasters; and (3) how these resources related to the functional areas of institutionalized disaster management. It was important to understand in how far the perception of the resources by the community and their actual use coincided. The survey included both a questionnaire as well as in-depth interviews.

The definition of "farmers" used in this study included anyone who worked or had worked on a farm in Sussex County, recognizing that there were employees, seasonal workers as well as family members other than the farm owner, who might have had valuable information for this study and, ideally, were able to provide multiple perspectives on the same events. However, for the purposes of this study, "farmers" did not include those engaged in farm support services, such as feed or equipment providers, who fall into separate professional categories. The definition of "farm" used to locate potential respondents was borrowed from the 2007 Census of Agriculture (USDA 2009, viii), which classifies a farm as "any place from which $\$ 1000$ or more of agriculture products were produced and sold, or normally would have been sold, during the census year."

In order to capture the historical context of previous disasters and resources used, a combination of sampling strategies was employed. During Ag Week in Harrington from 16 to 21 January 2012, a maximum variation strategy was employed to target participants with the widest possible range of experience - spatially across the county exposed to possibly different types of hazards but also in terms of type of farm operation. This was supplemented by a random sample survey in the five major townships: Seaford, Georgetown, Milford, Millsboro, and Laurel. Farmers were asked to complete a questionnaire and invited to a follow-up, in-depth interview.
The 81-question questionnaire included some basic community profile questions and then asked participants to respond to questions on their perception of farm community resources as well as those resources that they had actually employed in past disasters. The main part of the questionnaire was divided into four segments representing the four phases of the disaster management cycle: mitigation, preparedness, response, and recovery. Those four segments were each further subdivided into the four functional areas: coordination, assessments, communication, and implementation. Two questions were attached to each functional area: one question about general resources for that specific functional area, and another more specific question on resources related to a particular activity in that disaster management phase. These two separate types of questions - general and exhibit - intended to confirm that the questions had been understood. They also served as an entry point for further clarification during the in-depth interview. Keeping in tradition with qualitative research, some open-ended questions were also included.

At the end of the survey, 33 questionnaires had been returned completed. They represented 33 farms in 10 locations, covering all ages, types of farming, and a diverse topography from inland and river to coast farming (Figure 2). In addition, a total of nine in-depth interviews were carried out. Seven of those were with farmers themselves, and two were conducted with Sussex County emergency services / Citizen Corps and a Georgetown fire company.

\section{Limitations}

Although the number of completed questionnaires fell within the expected minimum range, it largely confined the analysis to descriptive statistics. Finding participants after Ag Week in the five major townships of Sussex County also proved difficult. Usually, only one person per farm was available to complete the questionnaire, instead of the anticipated 5-10. This was attributed to the winter month. On arrival at a farm, the researcher was usually referred to the owner or manager, who was generally male ( $88 \%$ of respondents were male). Wives were reluctant to complete the questionnaire and referred to their husbands. This limited the range of perspectives on farm resources to mainly male owners and managers.

There was concern among respondents that the survey was going to be used to "inspire" more government regulations, which farmers strongly object to. It took the researcher extensive time to explain the project and for what purposes the data were going to be used. As with the survey during Ag Week in Harrington, it took two to three hours on average to find a participant and have one questionnaire completed. In addition, there seemed to be some degree of "survey fatigue." Some farmers showed the researcher other questionnaires they had just received in the mail from various research institutes.

This study was not about developing a survey tool for all community groups or individual citizens in Sussex County, who may have disaster management resources, but focused 


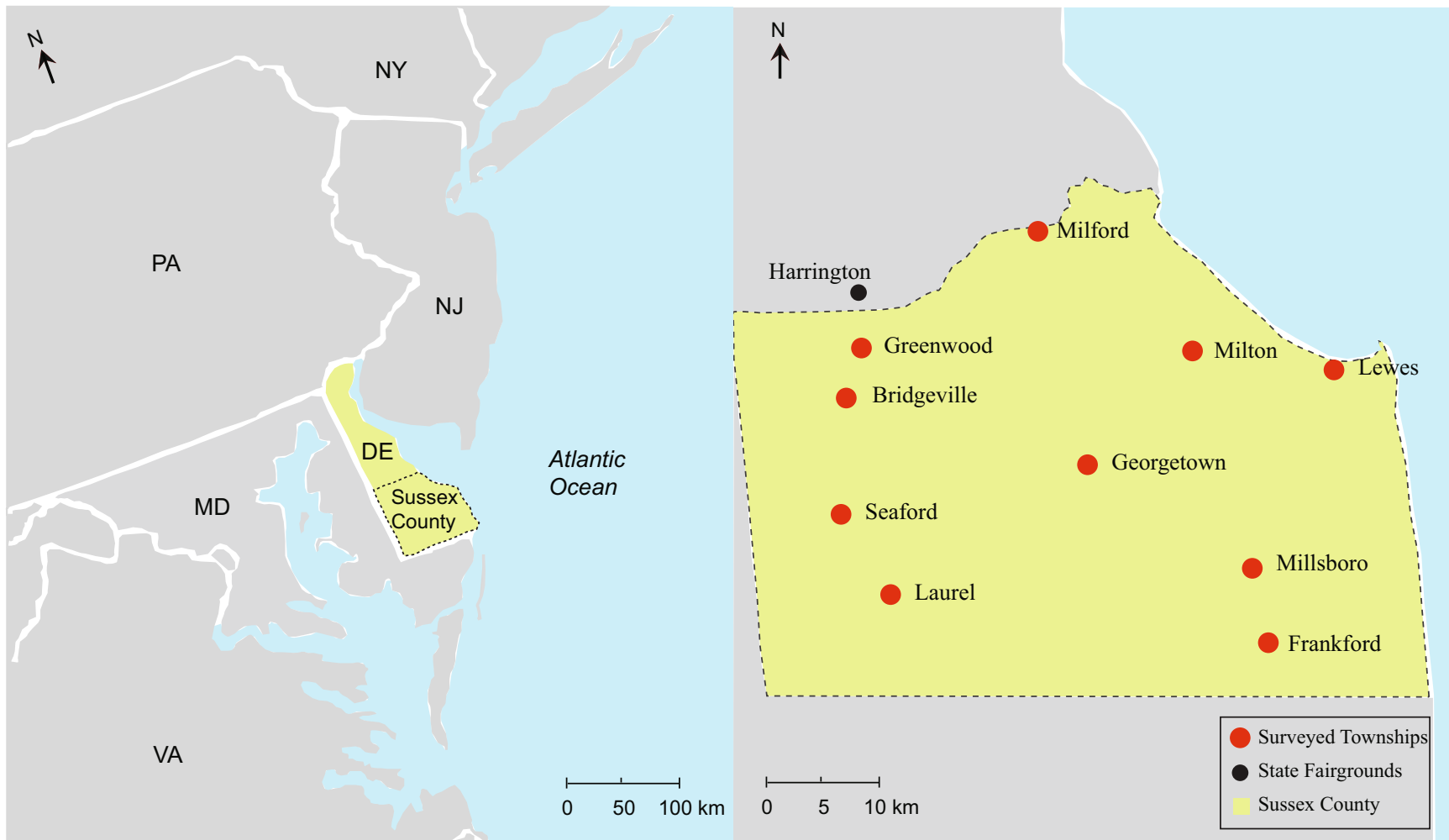

Figure 2. Surveyed locations in Sussex County, Delaware

on the farm community specifically. It also did not intend to suggest that its findings would necessarily be applicable to other farm communities. Every community will have its own distinct set of assets and challenges and different types and levels of resources. It was anticipated, however, that this study would provide an insight into how farm communities understand and use their own disaster management resources and provide a starting point for discussion on how these community resources could be leveraged better.

\section{Sussex County, Delaware: Disaster Profile}

According to historical data compiled by Sussex County Emergency Services, Sussex County with a total population of 197,145 (U.S. Census Bureau 2010) and situated on the Mid-Atlantic coast has experienced a wide spectrum of disasters over the past 250 years: floods, severe storms, tornados, earthquakes, droughts, and human-made disasters such as the release of hazardous material (Sussex County Emergency Operations Center 2004; Sussex County Emergency Operations Center 2010). In 2004, Sussex County was also affected by an avian flu outbreak that resulted in significant economic losses (Amis 2007). The top 10 hazards in terms of probability of future occurrence for the county include: release of hazardous material; extreme temperature; severe thunderstorm; winter storm; flood; drought; wildfire; hail; earthquake; and tornado (Sussex County Emergency Operations Center 2010). Exhibit questions for the questionnaire were designed with reference to some of the more severe events that affected Sussex County over the past 10 years, such as the 2004 avian flu outbreak, severe floods in 2006, and the winter storm of November 2010, with the expectation that more recent events would result in more comprehensive recollections. However, during the in-depth interviews, historical events as far back as Hurricane Hazel in 1954 were mentioned.

\section{Findings}

This section is organized in three parts corresponding to the three research questions of how the farm community in Sussex County perceived their disaster management resources, how they used them in the past, and how their resources related to functional areas of institutional emergency management.

\subsection{Perceived versus Actually Used Resources}

Before delving into the specifics of the findings, a comment is necessary on an observation related to general and exhibit questions. General and exhibit questions were used in the questionnaire in order to ensure that questions were understood, but also to better triangulate data. The responses 


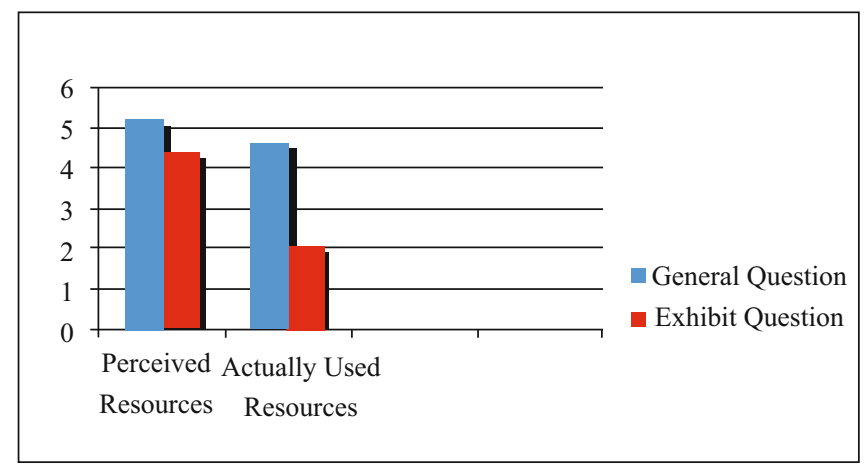

Figure 3. Farm community resources: Preparedness/Coordination in Sussex County, Delaware

showed that there were no apparent discrepancies between the ratings of general and exhibit questions - with the exception of coordination activities in the preparedness phase (Figure 3) and assessment activities in the preparedness, response, and recovery phases.

For coordination in preparedness as well as assessment in response, answers to the exhibit question for actually used resources showed a positive response while the general question did not. This indicates that the farm community in fact had used resources for those activities and in those phases, but this was not reflected in their perception. This suggests that there was an underestimation of resources in these areas.

Similarly, for assessment activities in both the preparedness as well as the recovery phase, overall positive answers were received to the exhibit question on perceived resources but not for the general question. This suggests that the farm community believed that it had positive resources for preparedness and recovery assessment. This could not be confirmed through instances of actual deployment. This may point to either an overestimation of resources or a lack of opportunity to date to deploy them. It was beyond the scope of this study to investigate any causal relationships. This area requires further analysis in future studies.

These observations on general and exhibit questions were important for the interpretation of the aggregate data on the four categories of activities throughout the disaster management cycle, which concealed these nuances. This is taken into account below, where the mean score point of the perceived and actually used responses was used to arrive at the aggregated results and served as the basis for the interpretation of the quantitative data (Table 1). They reflected answers provided to questions 18 to 81 , which offered a response scale from 1 "strongly agree"; 2 "somewhat agree"; 3 "neutral"; 4 "somewhat disagree"; 5 "strongly disagree"; 6 "don't know"; to 7 "doesn't apply." Where the mean score was smaller than 3 , it was interpreted as a positive response indicating the presence of a community resource. Where the score was greater than 3 , it was considered a negative response.

The survey found that, overall, perceived versus selfreported actually used resources were congruent with regard to the functional areas of communication and assessment. However, they diverged for implementation and coordination. As Figure 4 shows, the perception of available implementation resources was significantly higher during the preparedness and response phases than the respondents confirmed in their answers to the questions on the resources they had actually used before and after an event. Since the data did not offer any causal explanation, various reasons could account for this discrepancy, such as: the community had significantly more resources than it employed; the community had potential resources but had not had an opportunity to activate them; or the farm community overestimated its implementation resources. This could not be determined by this study and requires further investigation.

Another inconsistency that the survey highlighted concerned coordination activities in the preparedness phase specifically. Apparently, there was a positive identification of coordination resources that had been used in the past, but the perception of this category was negative. This seems to indicate an underestimation of potential coordination capacity, which was also revealed in the observation on answers to the exhibit versus general questions.

The findings of this study on perceived versus actually used resources of the farm community show that they overlapped with the exception of coordination in the preparedness phase, and assessment capacity in the response and recovery phases. Overall, in relation to the four disaster management phases and categories of activity, the farm community showed active collective engagement in implementing mitigation

Table 1. Questionnaire results in relation to the disaster management cycle in Sussex County, Delaware

\begin{tabular}{|c|c|c|c|c|c|c|c|c|c|}
\hline & \multirow[t]{2}{*}{ Resources } & \multicolumn{2}{|c|}{ Mitigation } & \multicolumn{2}{|c|}{ Preparedness } & \multicolumn{2}{|c|}{ Response } & \multicolumn{2}{|c|}{ Recovery } \\
\hline & & General & Exhibit & General & Exhibit & General & Exhibit & General & Exhibit \\
\hline \multirow[t]{2}{*}{ Coordination } & perceived & 4.5 & 4.5 & 5.2 & 4.5 & 4.3 & 3.6 & 5 & 4.9 \\
\hline & actually used & 5 & 5 & 4.7 & 2.1 & 4.4 & 3.7 & 4.7 & 4.9 \\
\hline \multirow[t]{2}{*}{ Assessment } & perceived & 4.2 & 3.7 & 3.5 & 2.4 & 3 & 3.3 & 4.3 & 2.4 \\
\hline & actually used & 4.3 & 5.4 & 4.6 & 3.4 & 5.2 & 3 & 4 & 5.4 \\
\hline \multirow[t]{2}{*}{ Communication } & perceived & 3.3 & 3.9 & 3.9 & 3.6 & 3.3 & 4 & 4.4 & 3.6 \\
\hline & actually used & 4 & 4.3 & 3.8 & 3.4 & 3.5 & 3.7 & 4.4 & 4 \\
\hline \multirow[t]{2}{*}{ Implementation } & perceived & 4.5 & 5 & 2.7 & 2.7 & 2.5 & 2.4 & 3.9 & 3.8 \\
\hline & actually used & 2.5 & 2.5 & 2.3 & 5.7 & 4.4 & 4.3 & 3.7 & 4 \\
\hline
\end{tabular}

Note: The mean scores smaller than 3 (in bold face) are interpreted as a positive response and indicating the presence of a community resource. 


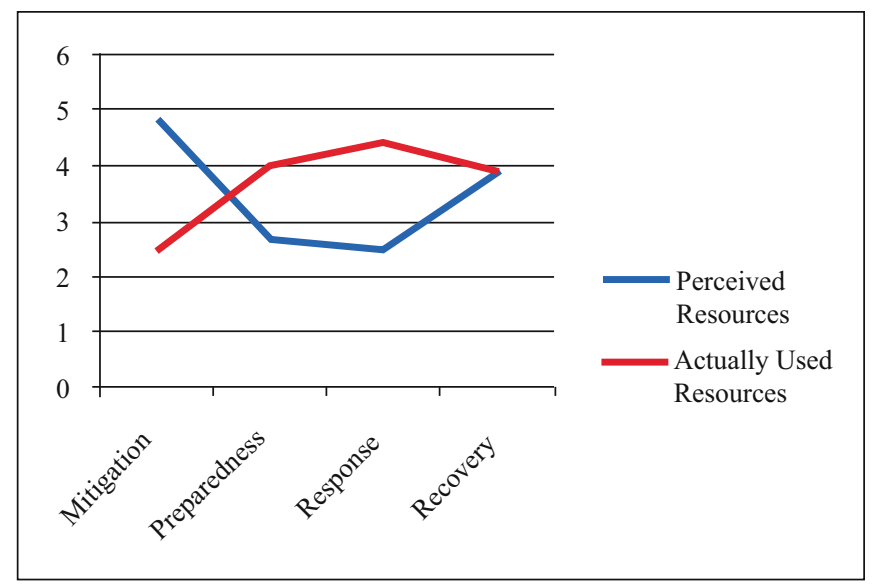

Figure 4. Farm community resources: Implementation in Sussex County, Delaware

measures; implementing and coordinating disaster preparedness; assessing and implementing a response; and carrying out assessments for recovery.

\subsection{When Resources Were Used for Collective Action}

This second part takes a closer look at when farmers used their disaster management resources for the benefit of the community.

\subsubsection{Coordination}

The farm community in Sussex County did not use a formal coordination mechanism for disaster management. There were no formal or organized meetings convened specifically for disaster-related activities. Throughout the fieldwork for this study, farmers themselves and other stakeholders emphasized their independent work style and the fact that there was no leadership structure. Everybody assumed whatever function needed to be filled whenever necessary. Fire services explained that, when there was a field fire, farmers converged spontaneously to help and, depending on what needed to be done to contain the fire upon their arrival on the scene, they would immediately take on that role. There were no preassigned roles and responsibilities. When functions were assumed, they were largely carried out independently and without supervision. One farmer commented that responses to incidents like field fires had been experienced so many times that farmers knew what needed to be done. This knowledge and experience continued to be handed done to the next generations of farmers.

When there was an imminent need that could not be managed by a farmer alone, farmers would informally meet to discuss what course of action to take. According to a number of respondents, farmers considered their everyday network to be within an approximately five-mile radius. This was what they considered to be their local community, where they knew everybody and helped each other. In advance of a snowstorm, they usually knew who of the farmers in the neighborhood would clear the roads close-by, if they did not fall under the responsibility of the Delaware Department of Transportation (DelDOT).

Coordination with emergency services in the preparedness and immediate response phases was more formalized. Some farmers had contracts for snow removal services with DelDOT, which clearly laid out their responsibilities and coordination requirements with the government. However, there were other farmers, who did not wish to be bound by a contract but still provided equipment and assistance to local emergency services. In those instances, there was structured communication with emergency services in the same way as was the case for contracted farmers. On requests for assistance, farmers communicated their availability. Sometimes they were reimbursed. However, as fire services explained, some declined reimbursements and, generally, the amount was often not commensurate with the expenses for the services provided.

A minority but significant number of respondents answered positively on questions related to collective coordination activities. For instance, 39 percent agreed that there was a forum to decide on mitigation measures collectively and some 28 percent confirmed that there was a farm representative to lead on mitigation. While the questionnaire responses did not provide details on the nature of those coordination fora, subsequent interviews and other information collected made reference to the role of the Farm Bureau, the Agriculture Cooperative Extension as well as other local and regional farm meetings, such as those organized by the Fruit and Vegetable Growers Association of Delaware and the Delmarva Poultry Industry, Inc., as venues to exchange information and discuss mitigation strategies. However, actual decision-making to implement mitigation measures seemed to remain at an individual farm level mostly within statutory requirements and standards.

The only positive results for collective coordination activities could be confirmed for the preparedness phase. Specific questions related to knowledge of equipment available in the community for specific tasks. Over 72 percent responded that they had knowledge of who in the community had road-clearing equipment that was ready to be deployed. The importance of knowing what equipment was available for emergency response was also confirmed and repeatedly made reference to during the interviews.

There was no formalized coordination structure for the use of farm community resources throughout the entire disaster management cycle. There were some formal and informal mechanisms that became active in the preparedness stage, particularly where resources were deployed in support of efforts by local emergency services.

\subsubsection{Assessment}

The study found that farmers drew on previous assessments, knowledge, and experience to make decisions particularly 
during the preparedness stage. They used their own lessons learned but also drew on outside expertise to inform their recovery strategies. For instance, 86 percent of farmers confirmed that they consulted with external farm experts on experiences in other regions of the United States in order to improve their own practices. Some 50 percent of all respondents affirmed that they had sufficient resources to carry out their own damage assessment after a disaster.

While the questionnaire only uncovered perceived but not actually used assessment resources for preparedness and recovery, interviews confirmed actually used resources in both of those two phases and the response phase. The analysis of the qualitative data concluded that most activities were carried out either in preparation of an insurance claim or in order to modify farming practices, or rebuild farm buildings with more disaster-resilient technology.

It has to be noted here that with some disaster management phases often running concurrently, the distinction particularly between recovery and mitigation activities is often blurred. Some recovery activities, which take into consideration lessons learned and best practices and in essence "build back better," can equally be classified as mitigation measures, as illustrated by the examples of modified farming practices or the rebuilding of farm buildings. Assessment activities of the farm community can be concluded to span the entire disaster management cycle.

Assessment activities are also a reflection of threat perceptions. What resources are deployed, when, for what types of events and to what degree are indicators of a community's risk identification. One of the researcher's assumptions prior to undertaking this study had been that any farm community would have a risk perception more closely aligned with the conclusions of emergency services and would, therefore, be more proactive in terms of disaster mitigation and preparedness than other segments of society. However, the findings of this study unveiled an unexpected reactive approach to disaster management in general. Repeated comments ranged from: "Why prepare for a disaster? If it's this bad, there is nothing else we can do but run"; to "Luckily we are not in the Mid-West or California, and don't have to worry about that [tornados, earthquakes]"; and "Flooding? We don't have any flooding problems in Sussex County!" Their risk assessments of a more severe event were low, but so was their risk perception of frequent and recurring emergencies, such as countywide flooding. This was a surprise as severe storms and floods ranked among the top five hazards both in the Sussex County Mitigation Plan as well as among the top five in the survey itself on self-reported types of events affecting farms in Sussex County. Less than five months prior to carrying out this study, Hurricane Irene had barely avoided a full hit on Delaware, and an earthquake with its epicenter in Virginia had reminded everyone that the Mid-Atlantic region, including Delaware, was located on a ridge between two of the earth's major tectonic plates. Considering that Sussex County is located on a sea-level plain with its highest elevation at
$74 \mathrm{ft}(23 \mathrm{~m})$ and experiences frequent and wide-spread flooding, comments by respondents that they did not understand the survey questions related to flooding and insisted that Sussex County was not affected by any flooding problems or threats were unexpected. One person commented that, during bad weather, including coastal storms, she would lock herself into her basement, which she considered to be the safest place on the property. Their house was located on the coastal river at sea level.

Low risk perceptions were also repeated with regard to questions on drought issues. Droughts rank number six in the County Disaster Mitigation Plan but were put in first place on self-reported disasters affecting farms in Sussex County. Yet, some farmers insisted that the county did not suffer from drought conditions at all in Delaware, as it was located on a plentiful aquifer and there was "more than enough water" available.

On other specific questions related to assessment activities, the following answers were provided. Responding to whether there was a preparedness plan for residents on the farm, livestock, and/or crops, only 40 percent of farmers answered affirmatively. Only 42 percent reported that they had used previous experience to assess risks to their farm before the arrival of last year's winter weather.

With regard to contact with emergency services during assessments, different experiences were reported during the response and recovery phases. In the immediate response phase, for instance, over 53 percent of farmers reported that they had been engaged by emergency services in some form in needs assessments. Examples that were mentioned related to reporting requirements for emergency services and insurance claims. After a field fire, the farmer and the fire chief would conduct a damage assessment together. In one instance, a farmer's prompt updates on damages and losses after a major storm had reportedly helped with providing the needed information to extend the state of emergency for the county. In contrast, for recovery and on the question whether the farm's damage assessment after the 2006 floods fed into a larger recovery plan for the community, only 9 percent agreed, while a significant number of 41 percent said they did not know, and 19 percent disagreed.

Communal channels are used to take advantage of outside assistance to inform recovery and mitigation strategies. Experience and lessons learned are used in the preparation phase. Contact with local emergency services on joint assessment activities is limited to the immediate response phase and then mainly for insurance claims.

\subsubsection{Communication}

Of the four categories, communication was the one that showed the least activity, both in the questionnaires and the interviews. Farm life in Sussex County, as in other places, has changed much over the past 50 years. Most respondents made reference to how an improved infrastructure in terms of communication technology and transportation had changed 
the cohesiveness of community life. The reliance that used to exist on neighbors helping each other in a remote countryside did not exist anymore to the degree that it used to, and occasions to congregate and exchange had become less frequent. For example, the tradition of taking the scrapple pot, used to boil hogs, from farm to farm has died out. This tradition used to be one of the main social events and also used to define one's understanding of neighborhood. In case of an emergency, farmers, like anyone else, now dial 911. According to one respondent, there were few instances, where someone would run to the farm next door for help. He explained that his first reflex was to dial 911. Professional emergency services arrived quickly and there was no need to call a neighbor.

The only specific question that received a positive majority response related to information exchange on mitigation measures. Over 53 percent agreed that there was some communications network in the community that they made use of to exchange information on mitigation measures. While no majority responded affirmatively to any of the other questions in the communications category, there were still a number of questions that received a high response rate. Over 41 percent confirmed that they had a contact list of all farmers in their community, but only 33 percent agreed that there was some communications network among farmers to communicate on an imminent disaster. This percentage for the preparedness phases increased to 43 percent on a communications network for farmers to exchange information on the response to a disaster. A communications network was clearly distinguished from a communications system. Only 26 percent agreed that they had some emergency communications system to exchange information with the rest of the farm community. This was also a conversation item during the interviews. Anecdotal evidence showed that farmers had informal communication networks - such as the truck stop in Laurel, where some made their way early in the morning to hear about the latest news and where they found out if help was needed anywhere, or they discussed an issue that needed to be tackled among neighbors informally over a cup of coffee. However, when it came to the means by which information was channeled, farmers continued to use face-to-face contact or telephone calls. There was no emergency communications system per se. Many farmers used basic walkie-talkies or two-way radios to communicate with farm personnel for dayto-day work in the field. These were not set up to speak with other farmers, and they also did not link with communication channels used by emergency services. When farmers worked with emergency services during an emergency, theydepending on the situation and individual arrangementswould receive a radio to communicate with the team for that particular deployment only.

Information exchange opportunities included farm association meetings and such fora as the annual Delaware Ag Week. The media, particularly farm newspapers such as The Delmarva Farmer and The Mid-Atlantic Poultry Farmer also played an important role in information sharing. However, none of these are designed to address disaster issues specifically. Farmers interviewed commented that, in relation to disasters, the media was one of the main sources of information to learn about best practices, particularly with regard to recovery and mitigation initiatives in other places.

One interesting finding concerned the perception of farmers with varying years of farming experience and their perception of information exchange. While one could assume that old established community relationships also corresponded to a higher degree of perceived and actual information exchange, the questionnaire responses dispelled that assumption. The majority of those who had lived or worked in the community for less than 20 years - as opposed to the average of over 40 years - responded more positively to having a communications network and venues for information exchange available. Nevertheless, conversations with and anecdotes of farmers who had only established themselves in the community over less than 10 years or so highlighted their difficulties with integrating into this old established farm community. This, as the data showed, did not correspond to having less perceived access to the farm community's communication and information exchange channels on disaster management issues.

Communication and information exchange on disaster related activities in the farm community was ad hoc and a reflection of how the cohesiveness of the farm community had changed with institutionalized emergency services now generally being the first point of contact and with better infrastructure facilitating increased mobility and self-sufficiency. Information sharing on recovery and mitigation strategies took place through more established channels, such as farm associations and the media.

\subsubsection{Implementation}

The strongest responses for perceived and actually used resources were received in the implementation category, covering all phases of the disaster management cycle with the exception of recovery. One of the few strongly agreed responses in the entire questionnaire referred to the question "Has the farm you are associated with learned from a previous disaster and taken measures to prevent damage and loss in the future?" This in essence was an implementation question linking recovery with mitigation. A total of 66 percent answered affirmatively to this question. The distinction between recovery and mitigation is difficult to delineate and an argument could be made that this response was evidence of the community's resources in both recovery as well as mitigation.

On specific implementation questions more than 58 percent believed they had sufficient resources themselves to protect farm assets and farm residents ahead of a disaster, and an equal percentage confirmed a communal stock of gasoline/ diesel that would be available in the event of a disaster. Over 69 percent reported to have taken measures to protect the farm before the start of the previous winter. Moreover, 
63 percent were confident that they had adequate resources to organize their own emergency response. This corresponded with interview responses and other field observations that the predominance of collective implementation activities took place in the immediate preparedness and response phases, but that also lessons learned were converted into mitigation measures. Preparedness activities included such measures as boarding up and securing farm assets on their own farms but also for neighbors who were in need of assistance. Mitigation strategies reflected those already mentioned under Assessments. Examples included switching to more flood or drought resilient crops, the purchase of additional farm machinery attachments to clear roads (snowplows), and reinforcing farm buildings. With regard to statutory requirements, 62 percent of farmers had put in place additional safety measures for chemicals that were not legally required.

Another important finding in the implementation category was that respondents decided to pool resources for the benefit of the whole community when individual resources had been exhausted, and/or the government response was too slow.

Implementation activities by the farm community focused on preparedness and response but took place in all four phases of the disaster management cycle. Confidence in own implementation resources was high. Table 2 provides a summary overview.

\subsection{What Types of Resources Were Used and How They Related to Institutionalized Emergency Management}

This section takes a closer look at the specific nature of the farm community's resources and how they relate to the traditional functional areas of institutionalized emergency management.

The survey revealed three broad categories of disaster management resources: (1) equipment/supplies; (2) experience/lessons learned; and (3) access to other community and professional networks. An overview is provided in Figure 5.

\subsubsection{Equipment/Supplies}

Equipment and supplies were the most often self-reported resources, which farmers deployed or declared as potentially actionable. This mainly related to heavy farm machinery used for road clearing, emergency vehicle recovery, and search and

Table 2. When resources were used for self-reported collective action in Sussex County, Delaware

\begin{tabular}{lcccc}
\hline & Mitigation & Preparedness & Response & Recovery \\
\hline Coordination & - & $\checkmark$ & - & - \\
Assessment & $?$ & $\checkmark$ & $\checkmark$ & $\checkmark$ \\
Communication & - & - & - & - \\
Implementation & $\checkmark$ & $\checkmark$ & $\checkmark$ & - \\
\hline
\end{tabular}

Note: The question mark signifies a negative aggregate mean score in the questionnaire responses. Some recovery activities can equally be qualified as a mitigation measure and may be evidence of both recovery and mitigation. rescue. Examples included snowplowing, accompanying fire engines to ensure clear and safe passage and rescue them or other vehicles when they get stuck, help electricity companies reach difficult to access areas after a storm and during power outages, as well as using machinery to lift heavy items and trapped farmers or others in need.

\subsubsection{Experience/Lessons Learned}

Some expertise was developed and carried forward over time and generations. At the same time, experiences of the same disasters also led to the processing of different lessons learned. The way in which farmers responded to a field fire was practiced behavior that hardly required instructions or communication anymore. Everyone knew what to do and assumed their role virtually automatically. This expertise was handed down to the next generation of farmers. Other disaster experiences led to divergent responses. For example, one farmer was so impressed as a young man by the impact of the 1979 snowstorm that he decided to heavily invest in mitigation measures. He calculated that the investment would pay off in the long run to reduce future damages and losses. Others, who had experienced the same event, made a more short-term profit calculation that did not take into consideration largerscale events and losses in the future. They decided against investing in more resilient farm structures or additional equipment. Some of these farmers would then rely on their neighbors, who had made those investments, to assist them, or expect government to provide those services. This was not only the case for century events but also for more regular emergencies like snowstorms and floods.

\subsubsection{Access to Other Community Networks}

Instances to augment their own response capacity by accessing other community and professional networks were also observed in this study. The avian flu outbreak in 2004 provided particularly informative insights into this phenomenon. Those affected and quarantined were supported by, among others, their church community, who delivered meals and groceries and also provided emotional support. Local businesses, including utility companies, agreed to defer and even reduce payments for those particularly hard hit by the financial losses. Schools facilitated home schooling for affected children. The ability to access these community networks was considered an important response mechanism to address basic immediate needs. These usually took place without contact and coordination with local emergency service.

One farmer commented that the combination of collective experience as well as access to other community networks ensured what he called "business continuity." In his view, local emergency management was sometimes "short-lived"with managers and other key personnel changing positions every few years and needing to reestablish relationships in the community. By contrast, the farm community and its approach to managing emergencies were firmly established 

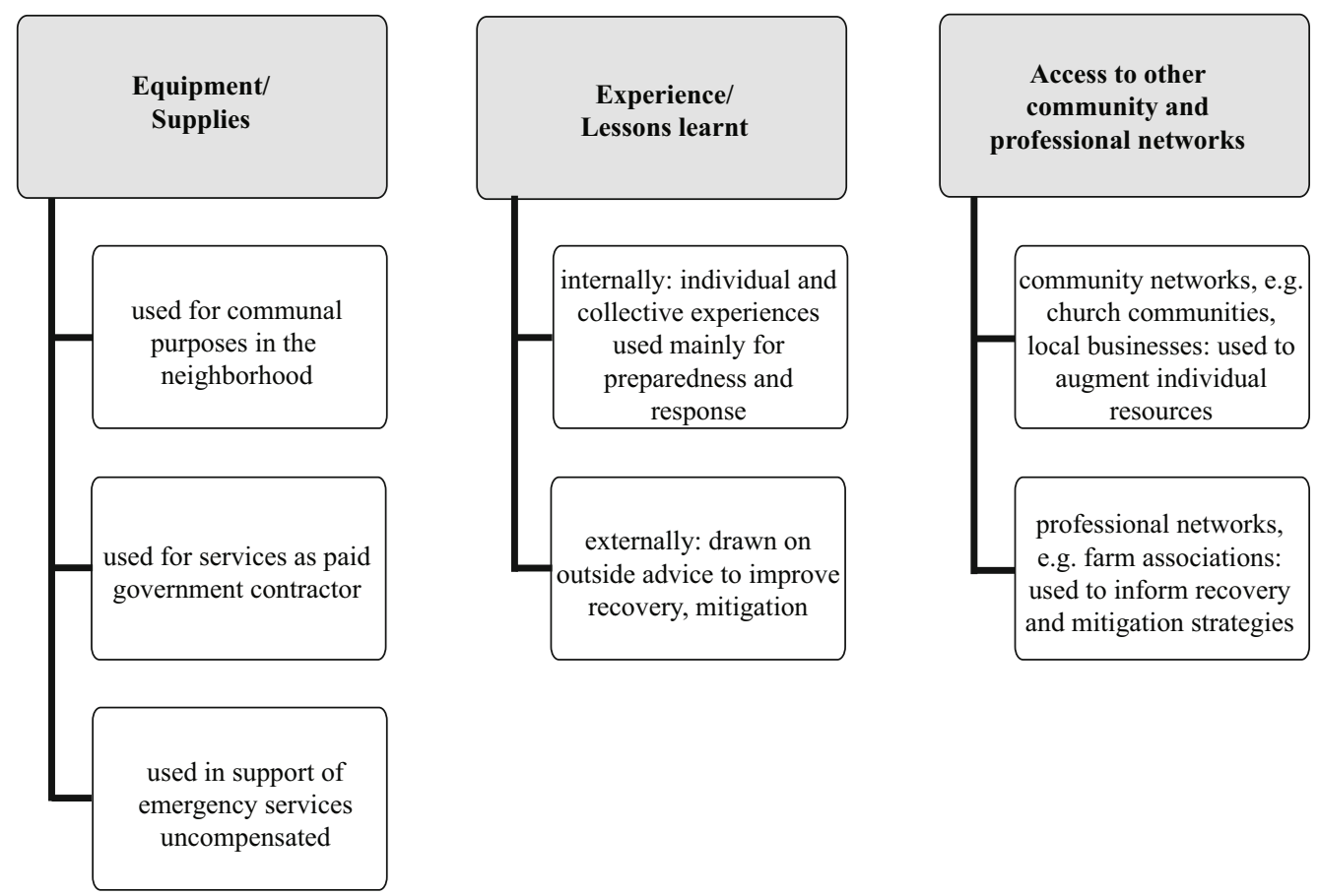

Figure 5. Types of farm community resources used in disaster management in Sussex County, Delaware

and easier to manage because people knew each other and were clear about their respective roles.

Various sections above already made reference to where at least two of these three categories of resources came in touch with the work of local emergency services. Access to other community or professional networks was not one of them. In order to gain a better understanding of how these three types of resources related to the traditional functional areas of disaster management as classified by NIMS and its categories of rural emergency management resources, the survey data was analyzed juxtaposing the three areas of the farm community's resources with the eight categories of NIMS (Figure 6). In response to the third research question "How do the resources of the farm community in Sussex County relate to the functional areas of institutional disaster management," there were clear areas of contact and overlap. However, the categorization of professional resources as defined by NIMS did not facilitate an overview and understanding of all of the actual and potential resources of the community.

\section{Discussion}

Hyman's construct of actionable social capital and Stone, and Weissbourd, Bodini, and RW Ventures, LLC's exploration of measurements and contributing factors leading to the formation of community assets assisted with the conceptual design for this study. The findings confirmed the importance they stressed of active versus inactive but potential community resources, as well as of other market forces that influence the deployment and scope of community resources. While other market forces - for example, the availability of crop insurance, an expanding public emergency management system, and a more accessible and expansive public infrastructure in general-have been encountered in this study and are examples of how the deployment of individual and collective farm disaster management resources has changed, it was not within the scope of this study to look into the specifics of this decision-making process. As Weissbourd, Bodini, and RW Ventures, LLC $(2005,10)$ commented, "market environments have distinct dynamics and levers of change that can affect what gets produced for whom and where." In order to better understand the phenomenon and dynamics of community disaster management resources, their proposition demands further examination. Therefore, future research may wish to investigate:

- the discrepancies between active and inactive but perceived farm disaster management resources in all of the four phases of the disaster management cycle; and

- the various market forces in the local disaster management economy that influence the deployment of a farm community's resources.

In relation to Green and Haines's (2012) conceptualization of community assets, four of the eight original types emerged as the disaster management capitals of the farm community in Sussex County. They were human, social, physical, and financial capital. The study also uncovered dormant resources, as well as some that may be both positive as well as negative in their impact on the community's capacity to manage a disaster (Figure 7). 


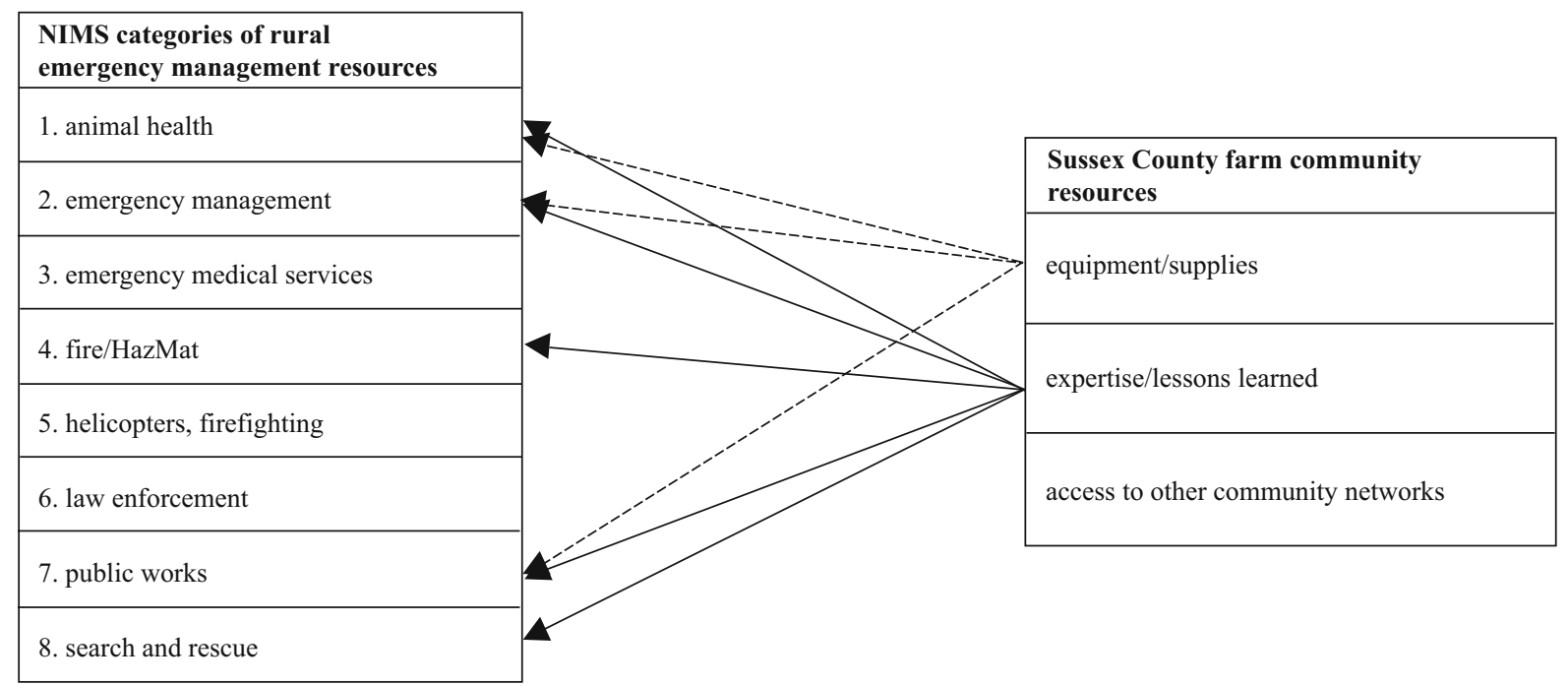

Figure 6. Farm community resources in Sussex County, Delaware, in relation to NIMS

The community's human capital drew on the experiences and skills acquired by the group while preparing for and responding to a disaster. It also included the demonstrated capacity to adapt mitigation best practices from other locations to the local context. The community's equipment and supplies, which helped maintain access to the local transport infrastructure, represented physical capital. At the same time, equipment and supplies also contribute to human capital, that is, the physical safety of community members. Financial capital - the ability to overcome a disaster with one's own resources but also the tapping into the social and professional networks of the community to receive assistance in times of crisis-was one of the most mentioned resources in this study.

Possibly because of a lack of opportunity, but not precluding overestimation, the study also located self-reported dormant resources for such activities as assessments and implementation. This poses a pertinent question in relation to those policies and strategies that are intended to boost only those capabilities that have "proven" to work. They may focus on active, visible resources that have been observed in recurring emergencies such as in winter snowstorms. However, this approach overlooks the full range of potential community capitals, which will be tested in larger-scale

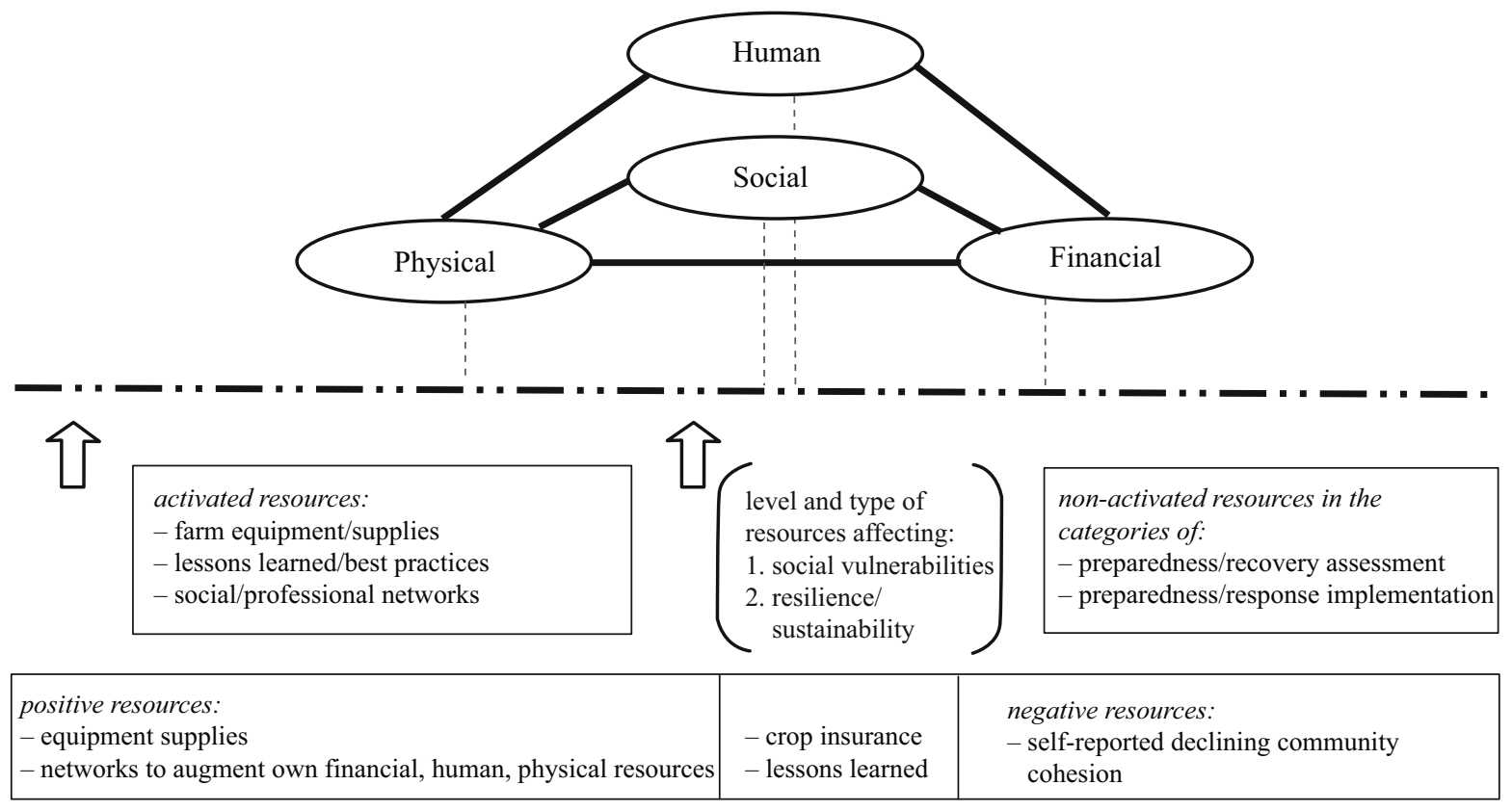

Figure 7. Farm community assets in Sussex County, Delaware 
national disasters and catastrophes, where the population may have to fend for itself for days, if not weeks. The powerful Tohoku earthquake and tsunami in Japan in 2011 was a stark reminder of this, and so is scenario planning for such issues as cyber terrorism and civil unrest.

The findings of this study also illustrate Portes's (1998) elaboration of positive and negative community resources. This became particularly apparent in relation to experiences and information processing of risks. While a modification of behavior may be suitable to a particular type of hazardssuch as the use of a basement safe room during a tornadothis may not be the best course of action for another type of hazard, for example, coastal flooding. In this sense, lessons learned could be both a positive but also a negative resource. Another example that was widely cited as the community's primary disaster response tool was crop insurance. Although this is a tremendously critical mechanism to save farmers from financial ruin and soften the economic impact of a disaster, as many of the respondents to this survey explained in response to questions on mitigation and preparedness measures, they felt they did not need to think too much about those since they had crop insurance. The response presented often was that crop insurance itself was their disaster preparedness and mitigation strategy. This raises the issue whether crop insurance may be a deflection from other preparedness and mitigation measures, which are not attempted because of the existence of subsidized insurance. Any planned disaster management activity should include a thorough analysis and understanding of its impact-positive but also negative - on a community's individual resources.

The understanding of this group to perceive their local farm community to be within an approximately 5 -mile radius has implications for any policy proposals that may wish to strengthen their capacity or connection to the institutional emergency management structure. The jurisdictional variations raise questions on what is to be understood by

- the definition of community in the context of disaster management; and

- how various community groups can be supported that are not located within congruent jurisdictions.

As this study found, the NIMS categorization of Resource Inventory Management for Rural Communities did not capture all of the actionable community assets. When pursing a disaster management approach that is intended to encompass the Whole Community, as is currently pursued by FEMA, a reconceptualization of these categories may be helpful to more comprehensively acknowledge a community's disaster management assets. The current categorization may be suitable to classify professional skills and equipment and supplies, but it does not facilitate the inclusion of all other available and potential resources. The extensive research that has been carried out to date on the concept of community assets may help inform such a process. Consideration should be given to reconceptualizing the NIMS categorization of Resource Inventory Management for Rural Communities.
Although rapid changes in society over the last 50 years have noticeably affected the cohesiveness and self-sufficiency of the farm community, their willingness to assist one another in times of immediate crisis seems undiminished. One respondent recounted a situation, where one farmer had had a bad harvest and, as a result, suffered significant financial losses that forced him to consider selling the farm. The respondent commented that, in the past, farmers would have rallied to help their neighbor out in a financial crisis like that. Instead, he explained, the farming business environment had become so intensely competitive that the farmer would now get a call from a neighbor not offering help but asking to have "first dibs" on the farm in the event it went up for sale. Some of these anecdotes provide insights into the changed cohesiveness of the farm community. This was also reflected in answers to some of the survey questions. For instance, 56 percent of farmers responded that their farms themselves responded to a disaster, with 17 percent indicating joint activities by emergency services and farms together. The farm community collectively came in third place with 11 percent. At the same time, where lives and livelihoods are immediately threatened - such as in farm fires - neighbors continue to respond promptly and without being requested to do so. It was beyond the scope of this study to examine the relationship of the apparent changes in the cohesiveness of the farm community and the conditions for deployment of disaster management resources to the benefit of the whole community. This, however, is clearly an important dimension in understanding the phenomenon and changing nature of the availability of community disaster management assets. Extensive research in community assets related to community economic development and the revitalization of urban neighborhoods could help establish a conceptual framework for monitoring the changing dynamics in community disaster management assets. Further research and policy developments may consider developing a framework for monitoring changes in a community that impact the availability of disaster management assets.

\section{Conclusion}

This study set out to investigate the nature of community disaster management resources. The findings are particular to the farming community in Sussex County, Delaware. Farm communities in other locations may offer some different responses and possess a slightly different set of community assets. Disaster management assets of other community groups are likely to be entirely different. However, the findings of this study offer insights into the significance of recognizing active as well as inactive community resources.

The first two research questions of this study queried how the farm community perceived and had actually used its own resources. The study found that there was a striking discrepancy between actually used and perceived community resources. Out of the four broad functional categories of 
activities - coordination, assessment, communication, implementation-perceived versus actually used resources were congruent for communication and assessment activities, but they diverged for implementation and coordination.

Farm community resources were primarily used for implementation activities and focused on the preparedness phase of the disaster management cycle. The types of resources used by the farm community fell into three broad categories: equipment/supplies; experience/lessons learned; and access to other community and professional networks.

The third research question queried how the resources of the farming community in Sussex County related to the functional areas of disaster management used by institutionalized emergency services. While there was an overlap with the NIMS categories of rural community emergency management resources, they did not facilitate an overview and understanding of all of the actual and potential resources of the local community. Policy recommendations based on the findings of this study propose, among others, resource mapping strategies to uncover both active and inactive resources, the use of existing communication channels to reinforce mitigation messages and information, as well as a reconceptualizing of the NIMS categories of Resource Inventory Management for Rural Communities to allow for the identification of all relevant local community resources.

Community capital is only as strong as the aggregate of its individual capitals. Although this study did not intend to examine individual disaster management capital, the process of the study design as well as the eventual findings clearly showed that community assets could not be separated from individual capital. The stronger the individual capital, the more is available to share with the community as a whole. This recognition should question the current role of citizens assigned by the professional disaster management community as mere recipients of assistance. It also infers that the strengthening of formal institutional structures alone is not sufficient. Community and individual assets need to be boosted simultaneously. A Whole Community approach can only be successful, if the disaster management assets of the whole community are thoroughly understood. A community-asset approach to disaster management offers a comprehensive conceptual framework to identify the full range of actionable community resources.

\section{References}

Amis, M. 2007. Avian Influential. DelawareToday. 12 October. http://www.delawaretoday.com/Delaware-Today/November-2007/ Avian-Influential/.

Board on Natural Disasters. National Research Council. 1999. Mitigation Emerges as Major Strategy for Reducing Losses Caused by Natural Disasters. Science 284 (5422): 1943-1947.

Bourdieu, P. 1986. The Forms of Capital. In Handbook for Theory and Research for the Sociology of Education, edited by J. G. Richardson, 241-258. Westport, CN: Greenwood Press.

Coleman, J. S. 1988. Social Capital in the Creation of Human Capital. The American Journal of Sociology. Supplement. Organizations and Institutions: Sociological and Economic Approaches to the Analysis of Social Structure. 94: S95-120.
Coleman, J. S. 1994. Foundations of Social Theory. Cambridge, MA: Belknap Press of Harvard University Press.

Cutter, S. L., B. L. Boruff, and W. L. Shirley. 2003. Social Vulnerability to Environmental Hazards. Social Science Quarterly 84 (2): 242-261.

Cutter, S. L., and C. Emrich. 2005. Are Natural Hazards and Disaster Losses in the U.S. Increasing? EOS, Transactions, American Geophysical Union 86 (41): 381, 388-389.

DHS (Department of Homeland Security). Office of the Inspector General. 2009. Improvement Needed in Federal Emergency Management Agency Monitoring of Grantees. OIG-09-38. Washington, DC: Office of Inspector General, Department of Homeland Security.

Dynes, R. R. 2006. Social Capital: Dealing with Community Emergencies. Homeland Security Affairs 2 (2). http://www.hsaj.org/?article=2.2.5.

FEMA (Federal Emergency Management Agency). 2010. MGT 339: Resource Inventory Management for Rural Communities - NonProcedure Participant Guide. Training material produced for the Department of Homeland Security.

FEMA (Federal Emergency Management Agency). 2011. A Whole Community Approach to Emergency Management: Principles, Themes, and Pathways for Action. FDOC 104-008-1/December 2011. Washington, DC: Federal Emergency Management Agency.

Furedi, F. 2007. The Changing Meaning of Disaster. Area 39 (4): 482-489.

Green, G. P., and A. Haines. 2012. Asset Building and Community Development, 3rd edition. Thousand Oaks, CA: SAGE Publications.

Guest, M. 2007. In Search of Spiritual Capital: The Spiritual as a Cultural Resource. In A Sociology of Spirituality, edited by K. Flanagan and P. C. Jupp, 181-200. Aldershot: Ashgate.

Haddow, G. D., J. A. Bullock, and D. P. Coppola. 2008. Introduction to Emergency Management, 3rd edition. Burlington, MA: Elsevier.

Hyman, J. B. 2008. Exploring Social Capital and Civic Engagement to Create a Framework for Community Building. In The Community Development Reader, edited by J. DeFilippis and S. Saegert, 225-233. New York: Routledge.

Lindell, M. K., C. Prater, and R. W. Perry. 2007. Introduction to Emergency Management. Hoboken, NJ: Wiley.

Murphy, B. L. 2007. Locating Social Capital in Resilient CommunityLevel Emergency Management. Natural Hazards 41 (2): 297-315.

O'Keefe, P., K. Westgate, and B. Wisner. 1976. Taking the Naturalness out of Natural Disasters. Nature 260 (5552): 566-567.

Portes, A. 1998. Social Capital: Its Origins and Applications in Modern Sociology. Annual Review of Sociology 24 (1): 1-24.

Putnam, R. D., R. Leonardi, and R. Nanetti. 1993. Making Democracy Work: Civic Traditions in Modern Italy. Princeton, NJ: Princeton University Press.

Putnam, R. D. 2000. Bowling Alone: The Collapse and Revival of American Community. New York: Simon and Schuster.

Quarantelli, E. L., and R. R. Dynes. 1971. Images of Disaster Behavior: Myths and Consequences. Working Paper No. 37. Disaster Research Center. The Ohio State University.

Stone, W. 2001. Measuring Social Capital: Toward a Theoretically Informed Measurement Framework for Researching Social Capital in Family and Community Life. Australian Institute of Family Studies. Research Paper No. 24.

Sussex County Emergency Operations Center. 2004. Sussex County Emergency Operations Plan. Sussex County, Delaware.

Sussex County Emergency Operations Center. 2010. 2010 MultiJurisdictional All Hazard Mitigation Plan Update. Sussex County, Delaware.

UN (United Nations). 2011. Global Assessment Report on Disaster Risk Reduction. Geneva: United Nations International Strategy for Disaster Reduction.

U.S. Census Bureau. 2010. State \& County Quickfacts: Sussex County, D.E. http://quickfacts.census.gov/qfd/states/10/10005.html.

USDA (United States Department of Agriculture). 2009. 2007 Census of Agriculture. Delaware, State and County Data, Vol. 1, Geographic Area Series, Part 8. AC-07-A-8.

Weissbourd, R., R. Bodini, and RW Ventures, LLC. 2005. Market-Based Community Economic Development. Washington, DC: Brookings Institution.

Open Access This article is distributed under the terms of the Creative Commons Attribution License which permits any use, distribution, and reproduction in any medium, provided the original author(s) and source are credited. 